\title{
Nutrients and foods consumed by New Zealand children on school days and non-school days
}

\author{
Paula M. L. Skidmore, Jennifer E. Rockell, Asher Regan, Noela C. Wilson and Winsome R. Parnell \\ Department of Human Nutrition, University of Otago, Dunedin, New Zealand
}

Efforts to improve the diets of children have largely focused on the school environment. In countries like New Zealand, where schools meals are not provided, it is particularly important to consider the role of the non-school environment (lunches sourced from home) on overall intake. Therefore, we compared food and nutrient intakes in New Zealand (NZ) children on school and non-school days.

Two thousand five hundred and seventy two children aged 5-14 years completed the NZ 2002 Children's Nutrition Survey. Dietary intake was assessed using computer-assisted multi-pass 24-h diet recalls in the home. Data were adjusted for survey weightings to be representative of the NZ population. The effect of day category on nutrient intake, and the likelihood of consumption of food categories was determined using linear and logistic regression.

There were differences in the proportion consuming some food groups between school days and non-school days, although the majority of nutrient intakes, including energy, did not differ by day category. Mean cholesterol intake was higher on non-school days (189 mg $v$. $170 \mathrm{mg}$ on school days); dietary fibre $(17 \mathrm{~g} v .15 \mathrm{~g}$ on non-school days), available carbohydrate $(262 \mathrm{~g} v .241 \mathrm{~g})$, in particular, sucrose and fructose, were higher on school days $(P<0.05$ for all). Hot chips were twice as likely to be consumed on a non-school day. Soft drink consumption was higher on non-school days. More children consumed Snack bars (OR for consumption compared to non-school day $=4.26)$, Fruit $(\mathrm{OR}=1.99)$ sandwiches $(\mathrm{OR}=2.79)$, biscuits/crackers $(\mathrm{OR}=1.6)$ and snack foods $(\mathrm{OR}=2.06)$ on school days.

Proportions of consumers of a variety of foods differed significantly between non-school and school days; a few nutrient intakes differed. This study indicates that family food, wherever it is consumed, is the mainstay of nutrition for NZ school children. 